\title{
Germ-free sea bass Dicentrarchus labrax larval model: a valuable tool in the study of host-microbe interactions
}

\author{
M. Schaeck ${ }^{1, *}$, E. De Swaef ${ }^{1}$, W. Van den Broeck ${ }^{1}$, S. Van Nevel ${ }^{2}$, N. Boon ${ }^{2}$, \\ N. De Geyter ${ }^{3}$, R. Morent ${ }^{3}$, K. Demeestere ${ }^{4}$, L. Duchateau ${ }^{5}$, C. Coulombet ${ }^{6}$, \\ F. Haesebrouck ${ }^{7}$, A. Decostere ${ }^{1}$
${ }^{1}$ Department of Morphology, Faculty of Veterinary Medicine, Ghent University, Salisburylaan 133, 9820 Merelbeke, Belgium
${ }^{2}$ Laboratory of Microbial Ecology and Technology (LabMET), Faculty of Bioscience Engineering, Ghent University, Coupure links 653, 9000 Gent, Belgium
${ }^{3}$ Department of Applied Physics, Faculty of Engineering and Architecture, Ghent University, Sint-Pietersnieuwstraat 41 B4, 9000 Gent, Belgium
${ }^{4}$ Research Group EnVOC, Department of Sustainable Organic Chemistry and Technology, Faculty of Bioscience Engineering, Ghent University, Coupure links 653, 9000 Gent, Belgium
${ }^{5}$ Department of Comparative Physiology and Biometry, Faculty of Veterinary Medicine, Ghent University, Salisburylaan 133, 9820 Merelbeke, Belgium
${ }^{6}$ Ecloserie Marine de Gravelines, Gravelines, France
${ }^{7}$ Department of Pathology, Bacteriology and Poultry diseases, Faculty of Veterinary Medicine, Ghent University, Salisburylaan 133, 9820 Merelbeke, Belgium

\begin{abstract}
A thorough understanding of host-microbe interactions is crucial for more efficient disease management in the marine larviculture industry. As demonstrated in terrestrial animal research, gnotobiotic systems (involving animals cultured in germ-free conditions or inoculated with known microorganisms) are excellent tools to extend our understanding of the mechanisms involved in host-microbe interactions and allow the evaluation of new treatments for diseases. In this study, we introduce a germ-free European sea bass Dicentrarchus labrax larval model, independent of the continuous addition of antimicrobial agents. This model has an experimental set-up that allows addition of live feed to the larvae without compromising the germ-free status. This model will facilitate and render aquaculture research more effective in terms of mitigation fish larval diseases.
\end{abstract}

KEY WORDS: Aquaculture $\cdot$ Gnotobiotic $\cdot$ Pathogen $\cdot$ Larvae

\section{INTRODUCTION}

Food security is a pressing global concern as the world's population is estimated to reach between 8.5 and 10.5 billion by 2050 . With capture fisheries becoming increasingly unsustainable due to overfishing, aquaculture is projected to overtake the former in supplying the world's marine protein requirements in the near future (FAO 2014). However, disease out- breaks impede the sustainable development of global aquaculture (Vadstein et al. 2013). Although treatment with antibiotics has been the main strategy for controlling infectious diseases, there is increasing acknowledgment of its limitations in terms of potential toxicity, the engenderment of resistance and residues, as well as environmental impairment (Alderman \& Hastings 1998, Jones et al. 2004, Cabello 2006, Sapkota et al. 2008). As a result, there is a trend 
towards more strict regulations on the use of antibiotics in the aquaculture sector (Subasinghe et al. 2001, Romero et al. 2012), hence calling for alternative, sustainable methods to which the aquaculturist can resort for preventing and controlling disease outbreaks. Several environmentally friendly prophylactic disease treatments have been the focus of recent research, i.e. probiotics, prebiotics, vaccines, immunostimulants or antimicrobial peptides (Merrifield \& Ringø 2014).

A judicious and scientifically supported application of the abovementioned alternatives warrants a thorough testing of their efficacy and safety under standardized and controlled experimental conditions (Smith et al. 2003). However, the stochastic colonization of larvae by microorganisms may hinder the establishment of a reproducible experimental set-up by generating high inter-individual and inter-batch variability in the composition of the standing microbial community. Hence, from a microbiological point of view, iterating experimental conditions using conventional animals is almost impossible (Fjellheim et al. 2012). The development of test systems in which the researcher has complete control over the microbial community structure, by adopting a germ-free or gnotobiotic model, was revolutionary in this respect. As already demonstrated in multiple terrestrial animal studies, gnotobiotic models are an excellent tool to extend our understanding of (1) the nutritional requirements of host organisms, (2) host-microbe interactions and (3) host metabolic functions (Gordon \& Pesti 1971, Wostmann 1996, Marques et al. 2005). Despite the significant increase in the use of fish as experimental animals during the last decades (Marques et al. 2005, Schaeck et al. 2013) and the stressed importance of raising aquatic organisms gnotobiotically (Bates et al. 2006, Rekecki et al. 2009), the current know-how of rearing gnotobiotic aquatic organisms is much more limited compared to the more traditional mammalian laboratory animals. To our knowledge, only a handful of studies have reported the successful derivation of gnotobiotic marine fish species (Baker et al. 1942, Munro et al. 1995, Rawls et al. 2004, Dierckens et al. 2009, Forberg et al. 2011; for a review, see De Swaef et al. 2015). However, not all of these models included a system for axenically feeding the larvae, and some used only culture-based techniques to verify microbial status, with the potential of falsely claiming a germfree status. Furthermore, all models relied upon a continuous addition of antimicrobial agents to the rearing water to safeguard the germ-free condition, with the exception of the zebrafish Danio rerio and Atlantic cod Gadus morhua models (Rawls et al. 2004,
Forberg et al. 2011). The use of antimicrobial agents may elicit unwanted and unknown interactions with the target organism (Marques et al. 2006). Furthermore, the envisaged microorganisms need to be made resistant to the antimicrobial agent by multiple in vitro passages, which may have an impact on pathophysiological traits of the microorganism under study (Fux et al. 2005, De Swaef et al. 2015).

In this respect, the aim of our study was to develop a standardized germ-free sea bass larval model system, independent of the continuous addition of antibiotics and allowing germ-free feeding, which will facilitate the study of host-microbe interactions.

\section{MATERIALS AND METHODS}

All experiments were approved by the Ethical Committee of the Faculty of Veterinary Medicine and Bioscience-Engineering, Ghent University (no. EC2013/19). All procedures were conducted aseptically. Therefore, all materials and liquids were autoclaved $\left(120^{\circ} \mathrm{C}, 20 \mathrm{~min}\right)$ or purchased sterile, and all manipulations were performed within a microbiological safety cabinet class II or a barrier isolator with a glove system (G(ISO)-T3, TCPS). Artificial autoclaved sea water (AASW, Instant Ocean®) and filtered (0.2 $\mu \mathrm{m}$, Sartopore Pt MidiCaps, Sartorius) AASW (FAASW) were adjusted to a salinity of $33 \mathrm{ppt}$ and a temperature of $16 \pm 1^{\circ} \mathrm{C}$.

\section{Egg acquisition}

Naturally spawned European sea bass eggs, aged 24-48 h post fertilization, were obtained from the 'Ecloserie Marine de Gravelines' (Gravelines, France). The viable, hence buoyant, eggs were skimmed off in the hatchery. Upon arrival, the eggs were collected on a nylon sieve (mesh size $300 \mu \mathrm{m}$ ) and gently rinsed with AASW (Salvesen \& Vadstein 1995).

\section{Short-term study}

A short-term study was initially carried out employing 4 disinfecting agents to assess their capability to sterilize eggs and yield germ-free larvae at $1 \mathrm{~d}$ post-hatching (dph) with no marked adverse effects on hatching ratio. Four different disinfecting agents were tested, with varying concentrations and contact times: glutaraldehyde (Salvesen \& Vadstein 1995, Dierckens et al. 2009), hydrogen peroxide, non- 
thermal plasma (NTP; Jacobs et al. 2011, De Geyter \& Morent 2012) and ozone, generated in dry air by a LAB2B ozone generator (Ozonia). All adopted protocols are listed in Table 2 (in the 'Results'). Hatching ratio for each incubation bottle was expressed using a semi-quantitative score: 3 (hatchability comparable with the eggs in the non-treated incubation bottles), 2 (hatching $>50 \%$ of the control), 1 (hatching $<50 \%$ of the control) and 0 (inability to hatch).

\section{Long-term study}

Approximately 200 eggs were transferred to a $50 \mathrm{ml}$ Falcon (Greiner Bio-One) tube, filled with $40 \mathrm{ml}$ of a $400 \mathrm{ppm}$ glutaraldehyde solution (50 wt \% solution in water; Merck), prepared with AASW. After 3 min of stirring, the eggs were transferred to a second $50 \mathrm{ml}$ Falcon tube, again filled with $40 \mathrm{ml}$ of a $400 \mathrm{ppm}$ glutaraldehyde solution. After $3 \mathrm{~min}$, the eggs were rinsed in 2 successive baths of AASW and were then collected and placed into $500 \mathrm{ml}$ glass incubation bottles containing $400 \mathrm{ml}$ of FAASW supplemented with a mix of antimicrobial agents (Table 1). The control eggs underwent identical physical handling as the disinfected eggs but with no glutaraldehyde or antimicrobial agents added to the (F)AASW. A low level of filtered $(0.2 \mu \mathrm{m}$, Sartorius) air was provided to all incubation bottles. At $1 \mathrm{dph}$, the hatching ratio, the percentage of eggs hatched to total number of eggs was registered for every bottle. From each bottle, 24 larvae were stocked individually in sterile, polystyrene 24-well tissue culture plates (Greiner Bio-One), each well containing $2 \mathrm{ml}$ of FAASW. The well plates were placed in a barrier isolator with a glove system and from then onwards, all procedures were performed inside the isolator. From 1 to $16 \mathrm{dph}, 1 \mathrm{ml}$ of FAASW was changed every other day. From 7 to $16 \mathrm{dph}$, larvae were fed live sterile Artemia franciscana nauplii (EG type, INVE Aquaculture) every other day, 20-30 per well (Sorgeloos et al. 1986). Larvae were subjected to a circadian rhythm of 8:16 h light:dark. Larvae were monitored daily until $16 \mathrm{dph}$, whereupon all larvae were euthanized by immersion in an overdose of MS222 (SigmaAldrich). This protocol was performed twice in time, adopting different egg batches. Each time and for both the nondisinfected and disinfected eggs, four 24well plates were included.
Morphological analysis was performed to evaluate the impact of the germ-free conditions on larval growth and development. The standard body length was measured to the nearest $0.1 \mu \mathrm{m}$ using an Olympus SZX7 stereomicroscope and cell D software (Soft imaging system, Olympus NV) and defined as the straight distance between the tip of the snout and the most caudal part of the larva. This was done for 3 larvae per 24-well plate of batch 1 at 0, 5, 9 and $16 \mathrm{dph}$.

Statistical analysis of the hatching and survival percentages were performed using a fixed effects model incorporating batch, treatment and their interaction in the model and comparing treatment with the residual variance (generalized block design analysis) at the $5 \%$ significance level. The length measurements were compared between the germ-free and conventional larvae by a mixed model with plate as random effect and day, treatment and their interaction as categorical fixed effects. With a significant interaction, the treatment was compared for each of the 4 days separately using Bonferroni's adjustment for multiple comparisons, i.e. using a comparisonwise significance level of $0.05 / 4=0.0125$.

\section{Evaluation of germ-free status}

For the evaluation of the germ-free status of the larvae, water samples were retrieved from all incubation bottles at $1 \mathrm{dph}$ for the short-term study, and from all well units of every 24 -well plate at 7 and $16 \mathrm{dph}$ for the long-term study. The water samples were inoculated onto marine agar and in TSB $(+2 \% \mathrm{NaCl})$ and incubated at $17^{\circ} \mathrm{C}$ for $4 \mathrm{wk}$. In addition, a flow cytometer system was employed whereby water samples from the rearing water of 7 and 16 dph larvae were stained with a combination of SYBR Green I and pro-

Table 1. Antimicrobial agents that were included in the incubation bottles until hatching

\begin{tabular}{|c|c|c|}
\hline $\begin{array}{l}\text { Antimicrobial } \\
\text { agent }\end{array}$ & $\begin{array}{l}\text { Concentra- } \\
\text { tion (ppm) }\end{array}$ & Reference(s) \\
\hline Ampicillin & 10 & $\begin{array}{l}\text { Dierckens et al. (2009), } \\
\text { Forberg et al. (2011), } \\
\text { Situmorang et al. (2014) }\end{array}$ \\
\hline Rifampicin & 10 & $\begin{array}{l}\text { Dierckens et al. (2009), } \\
\text { Forberg et al. (2011), } \\
\text { Situmorang et al. (2014) }\end{array}$ \\
\hline Penicillin & 150 & Munro et al. (1995) \\
\hline Streptomycin & 75 & Munro et al. (1995) \\
\hline Oxolinic acid & 10 & Munro et al. (1995) \\
\hline Kanamycin & 10 & Munro et al. (1995), Rawls et al. (2004) \\
\hline Erythromycin & 10 & Munro et al. (1995) \\
\hline
\end{tabular}


pidium iodide for microbial viability assessment. Samples were loaded on an Accuri C6 flow cytometer (BD Biosciences). Cell counts were determined by measuring the number of particles in a set volume (25 $\mu \mathrm{l})$ after gating on green (FL-1) vs. red (FL-3) fluorescence plots in the BDC Sampler software (Swiss Federal Office of Public Health 2012, Van Nevel et al. 2013). FAASW was used to quantify the number of background particles.

\section{RESULTS}

\section{Short-term study}

The results of the various adopted disinfection protocols are listed in Table 2.

Eggs exposed to 2 successive rounds of 400 ppm glutaraldehyde treatment for 3 min resulted in germ-free larvae at $1 \mathrm{dph}$ and equally high hatching scores as the control eggs.

Sea bass eggs showed strong resilience against high concentrations of $\mathrm{H}_{2} \mathrm{O}_{2}$, and germ-free eggs were consistently obtained after a 5 min exposure to $10 \% \mathrm{H}_{2} \mathrm{O}_{2}$. However, upon working with these high concentrations, high inter-batch variability was observed in terms of hatching ratio.

Non-thermal dielectric barrier discharge and an atmospheric pressure plasma jet both resulted in 100\% mortality of the sea bass eggs at a concentration that was still too low for rendering the eggs germ-free.

Ozone treatment was not able to consistently engender germ-free eggs without a marked effect on hatchability. Indeed, this treatment elicited a negative impact on hatchability upon employing the concentration and contact times needed to render the eggs germ-free.

\section{Long-term study}

The hatching ratio of the disinfected and control eggs differed significantly ( $p=0.0122)$, exhibiting a mean \pm SE of $76.3 \pm 1.6 \%$ and $68.7 \pm 1.9 \%$, respectively. The survival of the germ-free and control larvae also differed significantly ( $\mathrm{p}<0.001)$, exhibiting a mean of $94.3 \pm 1.1 \%$ and $40.6 \pm 1.1 \%$, respectively.
Table 2. Disinfection protocols for European sea bass Dicentrarchus labrax eggs adopted in the short-term study, with their outcome in terms of hatching score (3: hatchability comparable to eggs in non-treated incubation bottles; 2 : hatching $>50 \%$ of controls; 1 : hatching $<50 \%$ of controls; 0 : inability to hatch) and germ-free status of $1 \mathrm{~d}$ post hatching (dph) larvae; for assays with hatching score $=0$, germ-free status was assessed using non-hatched eggs, $1 \mathrm{~d}$ after hatching of control eggs. GF/T: number of assays resulting in germ-free status/total number of assays for the protocol in question. DBD air: dielectric barrier discharge using air (Jacobs et al. 2011); APPJ argon: atmospheric pressure plasma jet using argon (Sarani et al. 2011)

\begin{tabular}{|c|c|c|c|c|c|c|}
\hline \multicolumn{2}{|c|}{ Disinfection protocol } & \multicolumn{4}{|c|}{ Assays (n) with hatching score } & \multirow{2}{*}{$\begin{array}{c}\text { Germ-free } \\
\text { status } \\
(\mathrm{GF} / \mathrm{T})\end{array}$} \\
\hline Dose & $\begin{array}{l}\text { Exposure time } \\
\text { (min:s) }\end{array}$ & 0 & 1 & 2 & 3 & \\
\hline \multicolumn{7}{|c|}{ Glutaraldehyde (ppm) } \\
\hline 150 & 03:00 & - & - & 3 & - & $0 / 3$ \\
\hline 400 & 03:00 & - & - & - & 1 & $0 / 1$ \\
\hline 400 & $03: 00+03: 00$ & - & - & - & 12 & $12 / 12$ \\
\hline 800 & 03:00 & 2 & - & - & - & $2 / 2$ \\
\hline \multicolumn{7}{|c|}{ Hydrogen peroxide (\%) } \\
\hline 2 & 05:00 & - & - & - & 3 & $0 / 3$ \\
\hline 4 & 05:00 & - & 2 & - & 1 & $0 / 3$ \\
\hline 8 & 05:00 & 2 & - & 1 & 3 & $0 / 6$ \\
\hline 10 & 05:00 & 5 & - & 2 & - & $7 / 7$ \\
\hline 12 & 05:00 & 10 & 1 & 4 & - & $14 / 15$ \\
\hline \multicolumn{7}{|c|}{ DBD air } \\
\hline- & 00:05 & - & 1 & 1 & - & $0 / 2$ \\
\hline- & $00: 10$ & - & 1 & 1 & - & $0 / 2$ \\
\hline - & $00: 20$ & 1 & - & 1 & - & $0 / 2$ \\
\hline- & $00: 30$ & 2 & - & - & - & $0 / 2$ \\
\hline \multicolumn{7}{|c|}{ APPJ argon } \\
\hline - & 04:00 & 1 & - & 1 & - & $0 / 2$ \\
\hline- & 06:00 & - & 1 & - & - & $0 / 1$ \\
\hline- & 08:00 & 1 & - & - & - & $0 / 1$ \\
\hline- & $10: 00$ & 2 & - & - & - & $2 / 2$ \\
\hline \multicolumn{7}{|c|}{ Ozone (mg l' ${ }^{-1}$ gas) } \\
\hline 2 & $04: 00$ & 2 & 1 & - & - & $0 / 3$ \\
\hline 4 & 02:00 & 1 & 2 & - & 1 & $0 / 4$ \\
\hline 3 & 03:00 & 1 & - & 2 & 2 & $0 / 5$ \\
\hline 3 & 04:00 & - & 1 & 3 & 3 & $5 / 7$ \\
\hline 4 & 03:00 & 26 & 2 & 11 & 11 & $45 / 50$ \\
\hline 4 & $04: 00$ & 2 & 2 & - & - & $3 / 4$ \\
\hline
\end{tabular}

From 9 dph onwards, standard length differed significantly between the conventional and germ-free larvae ( $p<0.001)$, with the divergence rate increasing towards the end of the experiment (Fig. 1). By $16 \mathrm{dph}$, the germ-free larvae had a mean \pm SD length of $5826.0 \pm 90.4 \mu \mathrm{m}$, which was significantly higher than what was noted in the conventional larvae $(5233.5 \pm 107.2 \mu \mathrm{m})$.

\section{Evaluation of germ-free status}

Absence of bacterial growth on cultivated agar plates or turbid incubated broth indicated that none 


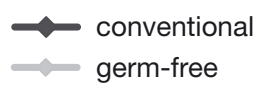

Fig. 1. Standard body length (mean $\pm \mathrm{SD}$ ) of larval European sea bass Dicentrarchus labrax at 1, 5, 9 and $16 \mathrm{~d}$ post hatching reared under conventional or germ-free conditions. Data are mean $\pm \mathrm{SD}(\mathrm{n}=4)$ with $\mathrm{n}$ representing the average of 3 larvae per well plate

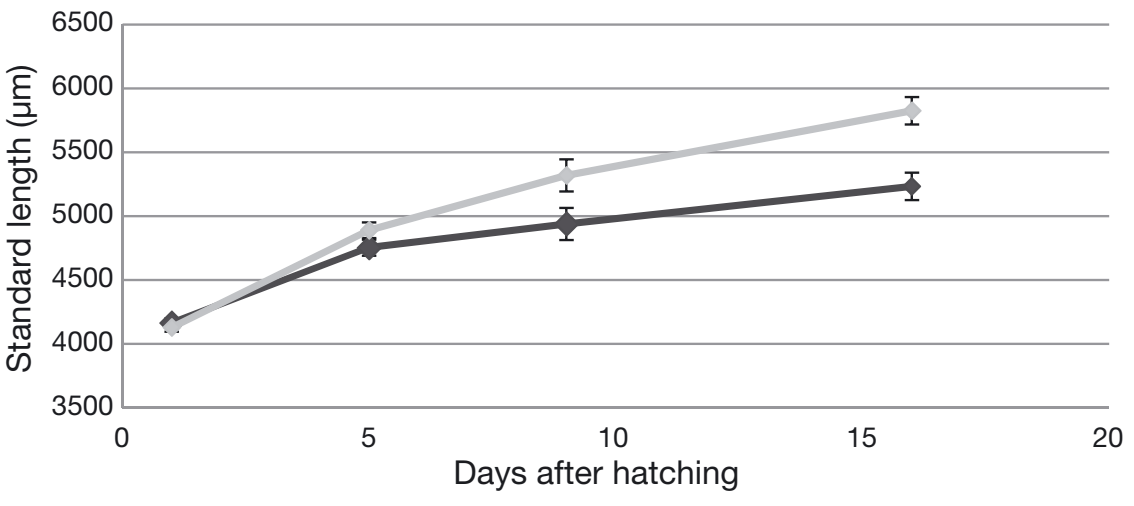

nowledged as a promising disinfectant tool, was included (Moreau et al. 2008, Dobrynin et al. 2009).

Hydrogen peroxide, one of the most commonly used disinfectants in aquaculture, either for eggs, larvae or live prey, reacts as a strong oxidizing agent (McDonnell \& Russell 1999). Up to now, only Douillet \& Holt (1994) succeeded in obtaining sterile cultures of red drum Sciaenops ocellatus eggs after a $5 \mathrm{~min}$ exposure to $3 \% \mathrm{H}_{2} \mathrm{O}_{2}$. An attempt to apply this protocol to other fish species failed in obtaining hatching eggs and germ-free larvae, indicating a high interspecies variability in sensitivity towards $\mathrm{H}_{2} \mathrm{O}_{2}$ (Douillet \& Holt 1994). In our study, we observed strong resilience against concentrations as high as $10 \% \mathrm{H}_{2} \mathrm{O}_{2}$. However, high inter-batch variability was observed in terms of hatching ratio. This could be related to the intrinsic egg quality, as working with suboptimal egg batches could exacerbate the negative effects on hatchability when adding an extra stress factor, such as high concentrations of disinfectant.

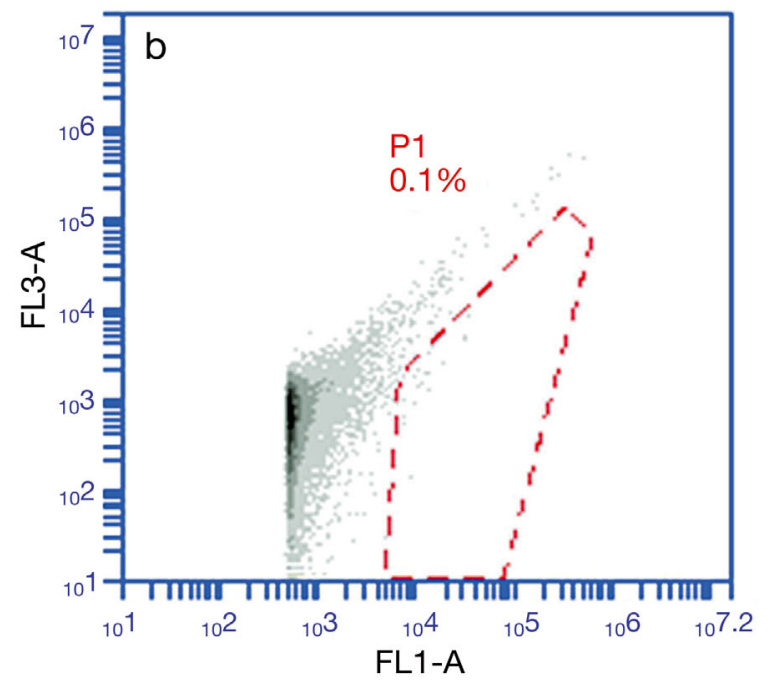

Fig. 2. Flow cytometer plots with gated events (marked area) to highlight bacterial contamination. Green fluorescence (FL1$A_{i} x$-axis) versus red fluorescence (FL3-A; $y$-axis). (a) Water sample (16 d post hatching, dph) from well housing conventional European sea bass Dicentrarchus labrax larvae. (b) Water sample (16 dph) from well housing germ-free sea bass larvae 
Ozone, a fungicidal, bactericidal, virucidal and sporicial agent, has been successfully applied to obtain germ-free sea bass eggs, as well as gilthead sea bream Sparus aurata, common dentex Dentex dentex and red porgy Pagrus pagrus (Can et al. 2012). In our study, some egg batches showed great resilience to high ozone concentrations, although there was a high inter-batch variability in terms of hatching ratio. This may be a result of ozone dissolved in sea water which increases the resistance of the chorion protein polymer to hydrolytic breakdown, and/or inhibits enzyme secretion from the hatching gland (Ben-Atia et al. 2007).

Over the past years, NTP, which is in general any plasma that is not in thermodynamic equilibrium, has emerged as a novel tool in medicine (Moreau et al. 2008, Kong et al. 2009, De Geyter \& Morent 2012), efficiently inactivating viruses (Yasuda et al. 2010), bacteria (Venezia et al. 2008, Kvam et al. 2012) and biomolecules such as DNA (Ptasińska et al. 2010). This inactivation occurs selectively, without burning the tissue, enabling the disinfection of living tissue without causing any damage (Fridman et al. 2006, Laroussi et al. 2012). In the present assay, $100 \%$ mortality was obtained at a concentration still too low for rendering germ-free eggs. This might be due to oxidative stress and damaged targeting enzymes, lipid membranes and DNA, caused by active shortand long-lived neutral atoms and molecules, generated by the NTP (Halliwell \& Gutteridge 2007, Davies 1987).

Glutaraldehyde, known for its strong bactericidal, sporicidal and virucidal properties, retains a high level of activity in the presence of organic matter, which is generally present in batches of fish eggs (Fraise et al. 2008). The ability to destroy bacterial spores is an extraordinary property, making it the disinfectant of choice (Salvesen et al. 1997). Dierckens et al. (2009), as well as our short-term study, used only 1 round of disinfection with $400 \mathrm{ppm}$ of glutaraldehyde for sea bass eggs (Salvesen \& Vadstein 1995, Salvesen et al. 1997). We found this dose to be insufficient to produce germ-free sea bass larvae. We investigated the effect of repeating the glutaraldehyde disinfection process as was already demonstrated to be effective by Forberg et al. (2011), whereby germ-free cod larvae were obtained. Two consecutive rounds of glutaraldehyde disinfection, followed by a $48 \mathrm{~h}$ immersion in a mix of antimicrobial agents (Table 1), did not induce negative effects on the hatchability of the sea bass eggs and engendered a germ-free larval status until the end of monitoring at $16 \mathrm{dph}$.
As a result of multiple tests, a protocol was established to generate and rear germ-free sea bass larvae in 24-well plates until $16 \mathrm{dph}$. Compared to existing models, various plus points of this technique are evident, as outlined below.

Firstly, not administering antibiotics post-hatching offers the advantage of being able to include nonpassaged bacterial isolates, thereby safeguarding the microorganism's original pathophysiological traits. The latter is important, as prior studies indicated that most acquired resistance mutations in bacteria confer a fitness cost (Melnyk et al. 2015). This may result in a longer generation time and altered metabolic activity, which are important determination factors for the establishment and the competitive capabilities of a strain in its microbial environment (Andersson \& Levin 1999, Levin et al. 2000).

Secondly, the individual housing of the larvae in 24 -well plates assures that the condition of an individual larva does not impact the other larvae. Indeed, Li et al. (2014) found that the mortality of gnotobiotic sea bass larvae challenged with Vibrio anguillarum was dependent on the number of dead fish in the vials at the moment of challenge. This indicates that individuals or their remnants can affect one another when housed together, explaining the high variability between replicates observed when working with group-housed larvae in challenge experiments. The successful rearing of sea bass larvae in a 96-well plate was already described by Panini et al. (2001). However, due to the small volume of the wells $(200 \mu \mathrm{l})$ and the rapid proliferation of opportunistic bacteria in the rearing water and host, the larvae were only incubated successfully until $10 \mathrm{dph}$. In our survey, we used 24-well plates, allowing the water volume to be 10 times higher $(2000 \mu \mathrm{l})$. In addition, larvae were reared under complete germ-free conditions. These adaptations allowed for successful rearing of the larvae until at least $16 \mathrm{dph}$. Survival rates of $95 \%$ were obtained, which are markedly higher compared to other experiments (e.g. Rekecki et al. 2009). We therefore hypothesize that larvae in $24-$ well plates will be able to survive for extended periods of time, considering the frequent water renewal, which prevented the accumulation of metabolites. The limiting factor when working with these microtitre plates will probably be related to the available space for larval growth. However, when research objectives would require prolonged maintaining of the larvae, 12- or 6-well plates may be implemented. In this respect, further research would indeed be very interesting for exploring the opportunities and boundaries of this model. 
Thirdly, besides being used to study the effects of different treatments on larval growth, survival and physiological traits, the well-plate system is most promising to evaluate larval condition or behavioural characteristics. These are key components in the analysis of phenotypes resulting from genetic mutations, gene knockdown approaches, chemogenetic lesions, drugs and toxins. Motor function can be analysed for multiple individuals simultaneously by acquiring video images showing larvae swimming in the wells of multi-well plates (Ahmad et al. 2012). These automatic systems could additionally be applied to monitor general well-being of an individual larva, alerting the researcher as to which larvae exhibit a high range of behaviours cueing for anxiety, stress or (pre-) death which may give rise to the ability to identify humane endpoints. As most experiments performed with larvae have the potential to cause pain, suffering or distress, opportunities for refinement need to be explored and suitable humane endpoints identified (Schaeck et al. 2013). This individual housing system may offer a tool to initiate the pinpointing of humane endpoints in fish larval experiments.

A variety of methods has been described to monitor the germ-free animal status. Most prior studies working on gnotobiotic models relied solely on culture techniques, which are rather time consuming and may give false-negative results when dealing with slow-growing, or viable but non-culturable, organisms (Davis 2014). Therefore, non-culture based methods should be used additionally to support the claim that the animals are germ-free. Recently, flow cytometry has become an established and highly valued technique for the microbial analysis of aquatic samples (Díaz et al. 2010, Forberg et al. 2011, Prest et al. 2013). The greatest advantage of flow cytometry, besides speed, reproducibility and large sample sizes, is that the quantification and identification of organisms that formerly could not be detected by culture techniques is now achievable (Hernlem \& Ravva 2007). In our model, we used culture-dependent techniques as well as flow cytometry, combining the best of both worlds and as such offering maximal certainty that this model effectively generates germ-free sea bass larvae.

The higher hatching and survival ratios of the germ-free larvae compared to conventional larvae are in accordance with other studies (Munro et al. 1995, Rekecki et al. 2009). The most obvious reason surface disinfection improves egg quality is that it prevents the proliferation of pathogens (Yoshimizu et al. 1995, Arimoto et al. 1996). In addition, fast pro- liferation of excessive amounts of bacteria on the egg surface may cause problems by reducing the exchange of gases and metabolic waste between the embryo and the environment (Vadstein et al. 1993, Salvesen \& Vadstein 1995).

The morphometric data coincide with the findings of Rekecki et al. (2009). Andersen (2002) postulated different mechanisms that could explain these differences in growth rate: (1) the production of toxic metabolic by-products by resident gut bacteria; (2) competition of the microbiota with the host for energy and amino acids; and (3) inflammation caused by the commensal bacterial biota.

To our knowledge, this is the first disinfection protocol, independent of the continuous administration of antimicrobial agents in the larval rearing water that is able to generate germ-free sea bass larvae up to $16 \mathrm{dph}$. This tool opens up possibilities for extending our knowledge on the mechanisms involved in host-microbe interactions and to evaluate formulated diets and disease treatments in a standardized manner. We anticipate that this model could be adapted to develop germ-free husbandry protocols for other fish species. However, due to interspecies variability in egg size, chorion characteristics and optimal rearing temperatures in marine fish, the optimal treatment is likely to be species-specific, emphasizing the need for further refinement when other teleost species are envisaged.

Acknowledgements. We gratefully acknowledge Prof. Dr. P. Simoens for critically reviewing the manuscript. Furthermore, we thank Patrick Vervaet for transportation support; the Laboratory of Aquaculture \& Artemia Reference Center (UGent) for their input; and Lore Vandermeersch (UGent) for help during the ozonation experiments. Finally, we acknowledge financial support from the Special Research Grant (Bijzonder Onderzoeksfonds, BOF12/GOA/022 and BOF12/BAS/070) of Ghent University, Belgium.

\section{LITERATURE CITED}

Ahmad F, Noldus LP, Tegelenbosch RA, Richardson MK (2012) Zebrafish embryos and larvae in behavioural assays. Behaviour 149:1241-1281

Alderman DJ, Hastings TS (1998) Antibiotic use in aquaculture: development of antibiotic resistance-potential for consumer health risks. Int J Food Sci Technol 33:139-155

Andersen DB (2002) Intestinal microbes: When does normality change into a health and performance insult? The Elanco Global Enteritis Symposium July 9-11, 2002, Greenfield, IN, p B3-B9

Andersson DI, Levin BR (1999) The biological cost of antibiotic resistance. Curr Opin Microbiol 2:489-493

Arimoto M, Sato J, Maruyama K, Mimura G, Furusawa I (1996) Effect of chemical and physical treatments on the 
inactivation of striped jack nervous necrosis virus (SJNNV). Aquaculture 143:15-22

Baker JA, Ferguson MS, TenBroeck C (1942) Growth of platyfish (Platypoecilus maculatus) free from bacteria and other microorganisms. Proc Soc Exp Biol Med 51: 116-119

Bates JM, Mittge E, Kuhlman J, Baden KN, Cheesman SE, Guillemin K (2006) Distinct signals from the microbiota promote different aspects of zebrafish gut differentiation. Dev Biol 297:374-386

Ben Atia I, Lutzky S, Barr Y, Gamsiz K, Shtupler Y, Tandler A, Koven W (2007) Improved performance of gilthead sea bream, Sparus aurata, larvae after ozone disinfection of the eggs. Aquacult Res 38:166-173

$>$ Cabello FC (2006) Heavy use of prophylactic antibiotics in aquaculture: a growing problem for human and animal health and for the environment. Environ Microbiol 8: 1137-1144

Can E, Karacalar U, Saka S, Firat K (2012) Ozone disinfection of eggs from gilthead seabream Sparus aurata, sea bass Dicentrarchus labrax, red porgy, and common dentex Dentex dentex. J Aquat Anim Health 24:129-133

$>$ Davies KJ (1987) Protein damage and degradation by oxygen radicals. I. General aspects. J Biol Chem 262: 9895-9901

> Davis C (2014) Enumeration of probiotic strains: review of culture-dependent and alternative techniques to quantify viable bacteria. J Microbiol Methods 103:9-17

De Geyter N, Morent R (2012) Nonthermal plasma sterilization of living and non-living surfaces. Annu Rev Biomed Eng 14:255-274

> De Swaef E, Van den Broeck W, Dierckens K, Decostere A (2015) Disinfection of teleost eggs: a review. Rev Aquacult, doi:10.1111/raq.12096

Díaz M, Herrero M, García LA, Quirós C (2010) Application of flow cytometry to industrial microbial bioprocesses. Biochem Eng J 48:385-407

$>$ Dierckens K, Rekecki A, Laureau S, Sorgeloos P, Boon N, Van Den Broeck W, Bossier P (2009) Development of a bacterial challenge test for gnotobiotic sea bass (Dicentrarchus labrax) larvae. Environ Microbiol 11:526-533

- Dobrynin D, Fridman G, Friedman G, Fridman A (2009) Physical and biological mechanisms of direct plasma interaction with living tissue. New J Phys 11:115020

Douillet PA, Holt GJ (1994) Surface disinfection of red drum (Sciaenops ocellatus Linnaeus) eggs leading to bacteriafree larvae. J Exp Mar Biol Ecol 179:253-266

FAO (Food and Agriculture Organization of the United Nations) (2014) The state of world fisheries and aquaculture. FAO, Rome

- Fjellheim AJ, Playfoot KJ, Skjermo J, Vadstein O (2012) Inter-individual variation in the dominant intestinal microbiota of reared Atlantic cod (Gadus morhua L.) larvae. Aquaculture 43:1499-1508

Forberg T, Arukwe A, Vadstein O (2011) A protocol and cultivation system for gnotobiotic Atlantic cod larvae (Gadus morhua L.) as a tool to study host microbe interactions. Aquaculture 315:222-227

Fraise AP, Lambert PA, Maillard JY (eds) (2008) Russell, Hugo \& Ayliffe's principles and practice of disinfection, preservation \& sterilization. John Wiley \& Sons, Chichester

Fridman G, Peddinghaus M, Balasubramanian M, Ayan $\mathrm{H}_{\text {, }}$ Fridman A, Gutsol A, Brooks A (2006) Blood coagulation and living tissue sterilization by floating-electrode dielectric barrier discharge in air. Plasma Chem Plasma Process 26:425-442

Fux CA, Costerton JW, Stewart PS, Stoodley P (2005) Survival strategies of infectious biofilms. Trends Microbiol 13:34-40

Gordon HA, Pesti L (1971) The gnotobiotic animal as a tool in the study of host microbial relationships. Bacteriol Rev 35:390-429

Halliwell B, Gutteridge JMC (2007) Free radicals in biology and medicine, $4^{\text {th }}$ edn. Oxford University Press, New York, NY

> Hernlem BJ, Ravva SV (2007) Application of flow cytometry and cell sorting to the bacterial analysis of environmental aerosol samples. J Environ Monit 9:1317-1322

Jacobs T, De Geyter N, Morent R, Desmet T, Dubruel P, Leys C (2011) Plasma treatment of polycaprolactone at medium pressure. Surf Coat Tech 205:S543-S547

Jones OA, Voulvoulis N, Lester JN (2004) Potential ecological and human health risks associated with the presence of pharmaceutically active compounds in the aquatic environment. Crit Rev Toxicol 34:335-350

> Kong MG, Kroesen G, Morfill G, Nosenko T, Shimizu T, Van Dijk J, Zimmermann JL (2009) Plasma medicine: an introductory review. New J Phys 11:115012

Kvam E, Davis B, Mondello F, Garner AL (2012) Nonthermal atmospheric plasma rapidly disinfects multidrugresistant microbes by inducing cell surface damage. Antimicrob Agents Chemother 56:2028-2036

Laroussi M, Kong MG, Morfill G (eds) (2012) Plasma medicine: applications of low-temperature gas plasmas in medicine and biology. Cambridge University Press, New York, NY

> Levin BR, Perrot V, Walker N (2000) Compensatory mutations, antibiotic resistance and the population genetics of adaptive evolution in bacteria. Genetics 154:985-997

Li X, Defoirdt T, Yang Q, Laureau S, Bossier P, Dierckens K (2014) Host-induced increase in larval sea bass mortality in a gnotobiotic challenge test with Vibrio anguillarum. Dis Aquat Org 108:211-216

> Marques A, Dinh T, Ioakeimidis C, Huys G and others (2005) Effects of bacteria on Artemia franciscana cultured in different gnotobiotic environments. Appl Environ Microbiol 71:4307-4317

Marques A, Ollevier F, Verstraete W, Sorgeloos P, Bossier P (2006) Gnotobiotically grown aquatic animals: opportunities to investigate host-microbe interactions. J Appl Microbiol 100:903-918

McDonnell G, Russell AD (1999) Antiseptics and disinfectants: activity, action, and resistance. Clin Microbiol Rev 12:147-179

Melnyk AH, Wong A, Kassen R (2015) The fitness costs of antibiotic resistance mutations. Evol Appl 8:273-283

Merrifield DL, Ringø E (eds) (2014) Aquaculture nutrition: gut health, probiotics and prebiotics. John Wiley \& Sons, Chichester

> Moreau M, Orange N, Feuilloley MGJ (2008) Non-thermal plasma technologies: new tools for bio-decontamination. Biotechnol Adv 26:610-617

Munro PD, Barbour A, Birkbeck TH (1995) Comparison of the growth and survival of larval turbot in the absence of culturable bacteria with those in the presence of Vibrio anguillarum, Vibrio alginolyticus, or a marine Aeromonas sp. Appl Environ Microbiol 61:4425-4428

Panini EB, Mylonas CC, Zanuy S, Carrillo M, Ramos J, Bruce MP (2001) Incubation of embryos and larvae of 
marine fish using microtiter plates. Aquacult Int 9: 189-196

Prest EI, Hammes F, Kötzsch S, Van Loosdrecht MCM, Vrouwenvelder JS (2013) Monitoring microbiological changes in drinking water systems using a fast and reproducible flow cytometric method. Water Res 47: 7131-7142

Ptasińska S, Bahnev B, Stypczyńska A, Bowden M, Mason NJ, Braithwaite NSJ (2010) DNA strand scission induced by a non-thermal atmospheric pressure plasma jet. Phys Chem Chem Phys 12:7779-7781

Rawls JF, Samuel BS, Gordon JI (2004) Gnotobiotic zebrafish reveal evolutionarily conserved responses to the gut microbiota. Proc Natl Acad Sci USA 101: 4596-4601

Rekecki A, Dierckens K, Laureau N, Boon N, Bossier P, Van den Broeck W (2009) Effect of germ-free rearing environment on gut development of larval sea bass (Dicentrarchus labrax L.). Aquaculture 293:8-15

Romero J, Feijoó CG, Navarrete P (2012) Antibiotics in aquaculture - use, abuse and alternatives. In: Carvalho E (ed) Health and environment in aquaculture. InTech, Rijeka p 159-198

Salvesen I, Vadstein O (1995) Surface disinfection of eggs from marine fish: evaluation of four chemicals. Aquacult Int 3:155-171

Salvesen I, Oie G, Vadstein O (1997) Surface disinfection of Atlantic halibut and turbot eggs with glutaraldehyde: evaluation of concentrations and contact times. Aquacult Int 5:249-258

Sapkota A, Sapkota AR, Kucharski M, Burke J, McKenzie S, Walker P, Lawrence R (2008) Aquaculture practices and potential human health risks: current knowledge and future priorities. Environ Int 34:1215-1226

Sarani A, Nikiforov AY, De Geyter N, Morent R, Leys C (2011) Surface modification of polypropylene with an atmospheric pressure plasma jet sustained in argon and an argon/water vapour mixture. Appl Surf Sci 257: 8737-8741

Schaeck M, Van den Broeck W, Hermans K, Decostere A (2013) Fish as research tools: alternatives to in vivo experiments. ATLA Altern Lab Anim 41:219-229

Situmorang ML, Dierckens K, Mlingi FT, Van Delsen B, Bossier P (2014) Development of a bacterial challenge test for gnotobiotic Nile tilapia Oreochromis niloticus larvae. Dis Aquat Org 109:23-33

Smith VJ, Brown JH, Hauton C (2003) Immunostimulation in

Editorial responsibility: David Bruno,

Aberdeen, UK crustaceans: Does it really protect against infection? Fish Shellfish Immunol 15:71-90

Sorgeloos P, Lavens P, Le'ger P, Tackaert W, Versichele D (1986) Manual for the culture and use of brine shrimp Artemia in aquaculture. Artemia Reference Center, Faculty of Agriculture, State University of Ghent, Ghent

Subasinghe RP, Bondad-Reantaso MG, McGladdery SE (2001) Aquaculture development, health and wealth. In: Subasinghe RP, Bueno P, Phillips MJ, Hough C, McGladdery SE, Arthur JR (eds) Aquaculture in the third millennium. Technical Proceedings of the Conference on Aquaculture in the Third Millennium, Bangkok, Thailand, 20-25 February 2000. NACA, Bangkok and FAO, Rome, p 167-191

Swiss Federal Office of Public Health (ed) (2012) Determining the total cell count and ratios of high and low nucleic acid content cells in freshwater using flow cytometry. Analysis method 333.1. The Swiss Food Codex (Schweizerisches Lebensmittelbuch). Swiss Federal Office of Public Health, Köniz

Vadstein O, Øie G, Olsen Y, Salvesen I, Skjermo J (1993) A strategy to obtain microbial control during larval development of marine fish. In: Reinertsen H, Dahle LA, Jørgensen L, Tvinnereim K (eds) Fish farming technology Proceedings of the First International Conference on Fish Farming Technology. Balkema, Rotterdam, p 67-75

> Vadstein O, Bergh Ø, Gatesoupe FJ, Galindo Villegas J and others (2013) Microbiology and immunology of fish larvae. Rev Aquacult 5:S1-S25

> Van Nevel S, Koetzsch S, Weilenmann HU, Boon N, Hammes F (2013) Routine bacterial analysis with automated flow cytometry. J Microbiol Methods 94:73-76

> Venezia RA, Orrico M, Houston E, Yin SM, Naumova YY (2008) Lethal activity of nonthermal plasma sterilization against microorganisms. Infect Control Hosp Epidemiol 29:430-436

Wostmann BS (1996) Germfree and gnotobiotic animal models: background and applications. CRC Press, Boca Raton, FL

Yasuda H, Miura T, Kurita H, Takashima K, Mizuno A (2010) Biological evaluation of DNA damage in bacteriophages inactivated by atmospheric pressure cold plasma. Plasma Process Polym 7:301-308

Yoshimizu M, Hyuga S, Oh MJ, Ezura Y, Ito S, Minura G (1995) Disinfectant effect of oxidant produced by ozonization of sea water on fish pathogenic viruses, bacteria, and ciliata. Dis Asian Aquacult 11:203-209

Submitted: June 22, 2015; Accepted: November 12, 2015 Proofs received from author(s): December 18, 2015 